\title{
Mothers for the Nation
}

\begin{abstract}
When women are healthy they are more able to give birth, which is indeed that for which society most yearns.

- CHONGQING BUREAU OF PUBLIC HEALTH, ANNOUNCING THE OPENING OF THE CHONGQING MATERNITY HOSPITAL, MAY 1944
\end{abstract}

The above sentence from the Chongqing Bureau of Public Health (CBPH) encapsulates wartime public health officials' beliefs about maternity: childbirth was at one and the same time a woman's greatest duty to the nation, and the greatest threat to her health. In other words, from the standpoint of state officials, no woman had a greater need for professional medical care than a laboring mother. Facts affirmed their belief in childbirth as a health threat: China's preeminent specialist in midwifery, Dr. Yang Chongrui (Marion Yang), estimated that 10 to 15 per 1,000 women, and 200 to 250 per 1,00o infants, died in or soon after childbirth, far exceeding the rates in developed countries. Once they survived infancy, Chinese children still faced a high probability of death from disease. Chinese delegates to the Conference of Far Eastern Countries on Rural Hygiene, held in Bandung, Indonesia, in August 1937, reported that 45 percent of rural children died before the age of five. In the public health ecosystem, Maternal and Child Health $(\mathrm{MCH})$ operated like a keystone species indicating the strength or weakness of the overall ecology. Health officials felt a deep attachment to and belief in sterile midwifery because of their genuine concern for the lives of women and children. They worked to assure that more mothers and children could survive childbirth and the tender first months of life even as bombs dropped and epidemics raged.

Although the available services never equaled actual need, they did significantly alter the medical landscape of Sichuan and further the medicalization of childbirth. Before the war, nearly 99 percent of births in Sichuan took place at home. The vast majority of these (over 88 percent) occurred with no midwife in attendance. ${ }^{2}$ During the war, the combination of educated health professionals, female medical workers, and foreign funding fueled a rapid construction of hospitals and 
health centers across Sichuan that shifted childbirth to the clinic. In rural areas most births still took place in homes, but rates of midwifery attendance increased, and these midwives were more likely to be young, unmarried women trained in sterile techniques.

Most of these young women came from eastern cities where hospital birth was already quite common, and where infant mortality rates were lower than the national average. ${ }^{3}$ Educated in germ theory at elite schools-principally the Peking Union Medical College (PUMC) or the First National Midwifery School, the latter established in Beijing in 1929-they, like nurses, contributed to the indigenization of scientific medicine. ${ }^{4}$ Their flexibility and willingness to adapt to local women's preferences enabled the young midwives to spread lifesaving delivery practices. At the same time their work gradually challenged the social power of elderly midwives, commonly called chanpo ("birthing grannies") or jieshengpo ("old women who receive the child"), whose prestige derived from their own successful births and record of success at delivering other women's children. ${ }^{5}$ While in China the masculinization of midwifery did not attend the medicalization of childbirth, as had occurred in other countries (as well as in China in the Song dynasty), the women who gained professional power in the twentieth century did so at the expense of another group of women. ${ }^{6}$

Midwives also played a central role in expanding the power of the central state in Sichuan. Because their work saved lives, young midwives proved to have particular staying power even in areas where local elites resisted change. Their knowledge of how to aid women through a momentous and potentially lethal event in their lives-parturition-granted midwives special access to women's bodies, homes, and hearts. Midwives, fully convinced of the power of their profession to bring people to health, gladly applied their skills to helping state health officials gain even further access to the people they served. The Nationalist government's move to Chongqing placed even rural areas of Sichuan Province within the reach of $\mathrm{MCH}$ workers, who, much like civilian and military nurses, developed relationships with expectant, laboring, and postparturient mothers that further strengthened the Sichuan people's place in the national community. Female midwives employed "scientific midwifery [to] connec[t] family reproduction to state politics."

While the Imperial Japanese Army seized city after city, women could not divorce their domestic and reproductive labor from national concerns any more readily than men could refuse to go to battle. The war's startling death toll intensified the focus on women as "mothers of citizens," who could birth the nation anew with their wombs' issue. Even the country's longest-running women's journal, the progressive Funü zazhi (Ladies' journal), had shifted to a stridently pro-natalist stance after male writers took control of the publication in $1921 .{ }^{8}$ During the War of Resistance, people's heightened desire for birth amidst all the death charged wives with the responsibility of creating not just healthy children but also healthy homes, managed according to scientific principles of cleanliness and order, in 
which all family members could flourish as dutiful, obedient citizens. It solidified homemaking as a woman's duty not just to her own family, but also to the "national family" - the literal translation of the term for "nation" (guojia) in modern Chinese. ${ }^{9}$ In discursive terms, the Chinese woman-herself the "Sick Woman of East Asia" - shouldered the responsibility of healing that same "Sick Woman" through delivering and bearing healthy children for the nation. Happy to play an important role for their nation in need, female midwives and orphanage volunteers worked to transfer women and children from the control of the household patriarch to the control of the state patriarch. In so doing, they became key players in bringing state power into the daily lives and domestic spaces of women and children, just as women had done in Meiji Japan and revolutionary France and were doing in contemporary Germany. ${ }^{10}$

\section{CHILDHOOD UNDER SIEGE}

The Japanese invasion endangered all Chinese citizens, but children often suffered the gravest injuries. Children were raped, injured or killed in air raids, orphaned, and captured by both Nationalist and Japanese press gangs looking for soldiers or laborers to carry military supplies. Children also frequently succumbed to infectious diseases to which they had less resistance than adults. In one instance, a reported 60 percent of refugee children got sick while in transit between Wuhan and Sichuan Province, and a high percentage of children under one year of age died in orphanages. Children's suffering had a gendered component as well: girls more frequently suffered rape, while military kidnappers almost exclusively targeted boys. ${ }^{11}$

This section takes children's vulnerability in war as a starting point and argues that childhood was also under siege in another sense. The national emergency compelled many adults to lay claim to children as the physical embodiment of the country's future. The Nationalist Party, with Song Meiling as its representative and spokeswoman, claimed parental authority over the country's "warphans" and built a network of orphanages wherein children learned to hate the Japanese and love the state and party. ${ }^{12}$ Forced to shoulder heavy responsibilities on behalf of the entire country and race, and inculcated with obedient patriotism, many of the children who survived the war nonetheless lost their innocence and independence.

The process of evacuating children from their own life-meaning began long before the war. Reformers in the late nineteenth and early twentieth centuries treated women's liberation as a means to a greater end-strengthening the nation; but in fact children were their ultimate targets. Agenda items that appeared on the surface to be for women-girls' education, the abolition of foot binding, and medical care for pregnant women-focused on an end goal of achieving "the nation's survival, ... its strength . .. , through the education of children." ${ }^{13}$ The concept of state ownership of a woman's womb and its issue found its most direct expression 
in orphan relief, which came under government patronage for the first time during the war. Relief workers focused on fashioning these "parent-free" children into worker-citizens impregnated with nationalism and ready to sacrifice all for their "parent-state." Just as Song Meiling stepped in as the figurative mother of all "warphans," the state she and her husband presided over defined itself as the rightful owner of children who had lost their biological parents in the tragedy of war. The war produced conditions under which the needs of the state took priority, and orphaned children were pressed into service for the national collective. ${ }^{14}$

A cogent if somewhat extreme expression of this idea came from Tang Guozhen, a Nationalist Party member, volunteer in the Wartime Association of Child Welfare (Zhanshi ertong baoyu hui) (WACW) and cofounder of the National Association of Chinese Women for the Comforting of War of Resistance Soldiers (Zhongguo funü weilao ziwei kangzhan jiangshi zonghui) (NACWCWRS). ${ }^{15}$ Tang advocated sending orphans to serve as soldiers on the front lines:

Special children, such as those who have not had good family education, and have then undergone long periods of vagrancy, as a matter of course do not have the good habits of typical children and controlling them can be particularly difficult. However, since they have long been bathed by the wind and rain, and warmed under the rays of the sun, they are healthier than typical children and their will is tremendously strong, so that not long after they arrive at an orphanage, all of their bad habits undergo quick transformation. Many vagrant children can already bear the responsibilities of a good troop commander [hao duizhang]. With a good education and a bit of extra effort to patiently lead them on the right path, one can certainly pick from among this group several children of outstanding talent who can become fresh troops for national salvation [jiuguo de shenglijun]. ${ }^{16}$

The exigencies of war pressed even young orphans into military service. In what appears to be a subtle move that nonetheless had decades of doctrine behind it, the state that first took the role as these children's protector now put their lives at risk. The Nationalist state's apparently contradictory position as protector-recruiter constituted a cooptation of the parental role, with the nation's rather than the children's interests at heart. Tang Guozhen had borrowed the language of "fresh troops for national salvation" from the contemporary press and used it to express ideas propagated by none other than the child development expert Tao Xingzhi and kindergarten educator Zhang Zonglin, both of whom advocated sending children into the battle zone to serve as covert counterintelligence agents. ${ }^{17}$ Indeed, some of the most enthusiastic soldier recruits came from war orphanages, while other child advocates argued that children could serve as military field nurses. ${ }^{18}$

Not all reformers and professional healthcare workers felt the same way. When Major General Zhou Meiyu discovered several eight- and nine-year-old "child soldiers" (wawa bing) serving as nurses in a military field hospital, she accused the commander of impropriety. The commander defended himself with the claim that 
the hospital needed these children's labor because all the adults had gone away to battle. Recognizing her defeat yet still concerned, Zhou recommended that the head physician care for all gravely wounded patients so that the children would not take fright upon witnessing their severe suffering. She also urged hospital staff to allow the children to sleep at night rather than require them to work the graveyard shift, since their growing bodies needed more rest. ${ }^{19}$ This story demonstrates that the shortage of laboring hands left even concerned advocates with no choice but to employ children as workers in fields fit for adults.

Another story about a "child soldier" illustrates awe at, rather than concern for, a young boy's dedication to national defense. The young college student Qing, who had volunteered with her classmates to comfort wounded soldiers in rural Guangxi Province, met a fifteen-year-old boy who had been separated from his parents and become a wounded "soldier" through an unfortunate occurrence. The fighting near his village in Zhejiang Province had sent his neighbors scattering, but his family stayed put since his father was too ill to flee. When the Communist guerrilla soldiers came through the village and needed help in navigating the local roads, this young boy bravely volunteered to help them, but in the process of leading the soldiers he was shot in a Japanese ambush. The guerrillas had to retreat quickly, so they carried the boy with them, getting farther from his home with every step. His father had already died, and he surmised that his mother had escaped danger, but the boy still had a bullet lodged in his anus and an unhealed wound with little hope of surgical treatment. Although Qing met this boy in a hospital, he still had not encountered a doctor who could offer him the medical care he needed. Moreover, since Guangxi was over a thousand miles from his home, he faced a slim prospect of reuniting with his mother before the war ended. Qing reported that the war had interrupted this boy's education and he was very eager to get back to school. Though he certainly would have had cause for anger and despair, she did not note any rancor in his heart and recorded his story to mark him as a war hero. ${ }^{20}$

Another boy whose war wound remained untreated almost certainly caused him consternation. Xu Chengzhen's little brother received a severe wound in Chongqing's notorious May 3, 1939, air raid when his elementary school was bombed and a piece of shrapnel flew into his inner thigh and groin area. Xu and her mother rushed him to the nearest medical clinic, where frantic doctors "could only treat people according to the degree of the severity of their wounds." Just as the doctors placed Xu's brother on the operating table, Japanese planes returned for a second round of bombs, and they aborted the procedure. In the end, the clinic ran short of supplies, and the doctor could only place a piece of gauze on the boy's wound. Xu and her mother then took him to a Chinese doctor in the countryside, who however failed to stanch the wound's infection before it left him permanently crippled and sterile. Even though he was not cured, the boy's medical 
costs and the fact that Xu's father had lost his livelihood in the bombings left the already poor family destitute for the duration of the war. ${ }^{21}$

Many families lived a bare existence on a razor's edge, and the loss of one breadwinner could easily shatter them. After her father died, thirteen-year-old Ye Qingbi had to migrate from Sichuan's Fuling County to Chongqing to find work. Unfortunately, she became a slave at the Yuhua Textile Factory, locked inside the factory with other teenage girls and forced to work twelve-hour shifts. Ye and her coworkers had only poor-quality food to eat, and slept on the cold, damp ground with hundreds of bedbugs. Years of overwork in such conditions gave Ye severe arthritis, but in order to be allowed to leave the factory and return home, where her mother could treat her with herbal medicines, she had to pay the factory owners. $^{22}$

Military families were particularly vulnerable to penury. A 1939 report from the New Life Movement Women's Advisory Council (WAC) in Chongqing claimed that "over 90 percent of military families are rendered destitute by the loss of their primary earner," and attempted to diagnose the problem. ${ }^{23}$ Interrupted or long-delayed remittances could leave the homebound family members hungry, and since it generally took six weeks for a letter to get from Chongqing to Beijing, such delays were the norm. ${ }^{24}$ Moreover Cui Xiangyu, wife of a military doctor, reported that air raids in Chongqing had destroyed postal facilities and "for months we could not receive either a letter or the promised money. My husband's salary was the family's sole income. Without it, we were starving." 25

As noted in chapter 3 , the greatest military burden already lay on poor families, and although these women volunteering in a government agency did not mention it, corrupt generals in the Nationalist military often deprived fighting men of their pay. More gravely, Japanese (as well as Chinese) troops frequently traveled long distances and, rather than tire their own soldiers with the strain of carrying supplies, stole livestock from villagers or kidnapped boys and men to serve as beasts of burden. ${ }^{26}$ The loss of an ox made a family's farm work much more strenuous, and likely had long-term consequences, since replacing a valuable animal was costly. In the case of kidnapping, a family not only lost a valuable laborer, but also received no pay while he was gone. ${ }^{27}$ Moreover, Chinese forced to work as coolies for the Japanese Army risked being killed by their own countrymen, since Chinese soldiers might fire indiscriminately on Japanese troops and their stolen coolies in surprise raids. ${ }^{28}$ Illness, accidents, opium addiction, sudden death, or flight from conscription gangs could also take a boy or man out of the fields and deprive his family of his labor and income. Coupled with the war era's steep inflation, this could bankrupt a family. ${ }^{29}$ Revisiting the question of Chinese nationalism during the War of Resistance in light of such economic hardship suggests that most people simply did not have the luxury of attaching themselves to an abstract concept 
such as the nation. They had to concern themselves with more-immediate necessities in order to survive. The people who helped them to survive-nurses, doctors, and midwives-stood the best chance of securing their attachment to a national community as a lived and embodied experience, expressed in human caring and intimate interactions.

Most middle-class people failed to comprehend the true needs of their poor compatriots, and instead worked to transform their outward behavior. As members of the working poor, military families became particular targets of reform. WAC women displayed a central feature of most wartime activism. Overwhelmingly from the middle and upper classes, these volunteers "aimed to 'civilize' their rural compatriots" and believed that compelling the poor to adopt a middle-class aesthetic, lifestyle, habits, and attitude would solve the problems of poverty. ${ }^{30}$ Women at the 1939 Chongqing meeting cast aspersions on military families for refusing to work, letting their children run free in the streets as unschooled vagrants, and failing to show proper understanding of and dedication to the war effort. Rather than reflect reality, these comments betrayed the women's own class sensibilities and failure to understand the life conditions of the poor and workingclass women they wished to reform. They placed their ultimate faith in the power of the state to intervene where the poor had "failed," and suggested that impoverished military families might ameliorate their condition by relinquishing their children to orphanages. ${ }^{31}$

The story of one woman who did just that shows that the state did not necessarily offer superior care. This woman, known as Peng-Wu shi (Mrs. Peng née $\mathrm{Wu}$ ), both came from and married into a wealthy family, but suffered a series of calamities that left her nearly penniless. She and her husband both became opium addicts, and bandits killed the family's primary earner (the eldest son, a cloth merchant) not long before her husband died. This left Peng bereft of the family land and with six sons to raise on her own. Her eldest surviving son was conscripted into the army, ran away, and received such a severe beating as punishment that the army refused to take him back; her second son had to go in his brother's stead. Peng sent out two more sons to adoptive families and placed her favorite, youngest son in a government orphanage with the hope of retrieving him once she regained solvency. Unfortunately, that son died of dysentery while in the orphanage. In the end only two of her six sons survived. ${ }^{32}$

Wartime conditions were so harsh that even staying at a mother's breast could not guarantee a child's survival. Cui Xiangyu, originally from Hubei, moved with her family to Sichuan in late 1938. Her husband, a military physician, spent the majority of the war far from his family while his wife took care of his parents in Chongqing and gave birth to their two sons, the second on the very day of an air raid. When that son fell ill with a disease he contracted while in the crowded air raid shelter, Cui had no time or money to seek medical assistance for him before 
he died in her arms, at just three years old. The remaining family of five continued to survive on her husband's single salary, which they supplemented with a family garden. ${ }^{33}$ So many pregnant women had to stuff themselves into crowded air raid shelters where contagious diseases flourished that in 1941 the Baoning Maternity Hospital announced the opening of an underground birthing room in Shapingba, just north of Chongqing. ${ }^{34}$ Poverty itself also took a toll on human life. Li Shuhua gave birth to six children during the war, but only two survived due to her constant hunger and the anxiety of living in extreme poverty in a frequently bombed city. As she put it, "A woman's body was just a machine for giving birth to babies, even though we had to bury most of them." ${ }^{35}$

The story of a mother who worked in the medical field further illustrates just how vulnerable young children were to infectious disease. Volunteer military nurse Yao Aihua lost her second son in the summer of 1943. Called to assist villagers in delivering children, Yao had had to leave her own child in the care of others. Someone fed him something that gave him an acute intestinal infection resulting in simultaneous vomiting and diarrhea. He died before his second birthday, and Yao recalled, "[W]e couldn't even buy a coffin for him. We were only able to wrap him up in a grass mat and ask people to bury him, but they buried him so shallowly that the wolves came to eat his corpse." ${ }^{36}$ This young child never had the chance to live up to his name, (Li) Ji Xing ("Continued Prosperity").

Such stories of poverty and hardship were so common during the war that they came to represent it in Cai Chusheng and Zheng Junli's widely acclaimed 1947 film, The Spring River Flows East (Yijiang chunshui xiang dongliu). Whereas Ba Jin's novel Ward Four reflected dramatic changes in traditional gender roles, this film underscored their perseverance in some popular culture. Despite the fact that more women than men volunteered to serve wounded soldiers on the front, in the film the husband, Zhang Zhongliang ("Loyal and Faithful Zhang"), joins the Chinese Red Cross, while the wife, Sufen, remains at home with her parents-inlaw and the couple's infant son, Kang'er ("Son of the Resistance"). Ironically, this puts her in a much more vulnerable position throughout the war, soon rendered more dramatic by the occupying Japanese soldiers' assassination of her father-inlaw, leaving the family without a male head of household. Despite her family's own scarcity of food and basic household goods such as soap, Sufen feels compassion for others and volunteers in an orphanage, where she fulfills her role as mother-of-the-nation by day, returning home to care for her mother-in-law by night. Several scenes show Sufen washing and mending clothing, or bathing and feeding the orphans-all with a look of contentment on her face, modeling the emotional labor of happily setting aside all of her own desires in order to work for others. Another scene shows her writing a letter for an illiterate refugee, who dictates the lines "Women have been blown to bits. Bodies have been found in pieces.... Our family is so destitute we can't even afford to buy coffins to bury our dead. We have to 
cover them up with matting." As Sufen writes, she repeatedly stares into the camera, a look of despair on her face. This scene, and many more like it, underscore the theme of women's vulnerability without male protection and erase the strength that Sufen repeatedly demonstrates as she cares for the entire family on her own.

Sufen's son, Kang'er, joins her in the orphanage until he is old enough (at age eight) to start his own job selling newspapers on the street. A scene in the second half of the film dramatizes his defenselessness. He is hawking papers when he encounters his father, now a business mogul recently returned from Chongqing and traveling in a private car, hanging a paper bill out of his car window to request a paper. A flood of desperate hawkers, including his own son, rush toward him, but Zhang Zhongliang does not even recognize the boy, now nine years old, whom the older sellers roughly push aside. At the end of a long day plying his newspapers on the streets of occupied Shanghai, Kang'er collapses in exhaustion. Though she is a diligent and conscientious mother, Sufen cannot save him from these hardships, and his now wealthy but profligate father cannot even recognize him. The Spring River Flows East emphasizes civilians' suffering, the functionality of state services (all the children and volunteers in the orphanage are full of smiles), and the traditional housewife's self-sacrificial role as caretaker of two generations-elderly parents-in-law and young children. ${ }^{37}$

\section{DELIVERING THE NEW NATION: MATERNAL AND}

\section{CHILD HEALTH IN WARTIME}

Although the war put grown children at greater risk, notable advancement occurred in combatting the primary vulnerabilities of young children: neonatal and infantile mortality caused primarily by neonatal tetanus. Over the course of the war, Chongqing health officials built eight Maternal and Child Health clinics and one large maternity hospital in the wartime capital, and $\mathrm{MCH}$ specialists across Sichuan hosted "well-baby" meetings and family hygiene clinics and visited women in their homes to perform deliveries and both pre- and postnatal checkups. As with nursing, the wave of refugees had unleashed a new supply of personnel, and the threat of national extinction prompted an increase in state funding. Thus, the war placed Chinese children at greater risk, but also created the conditions under which the field of medicine designed to protect them witnessed important achievements.

The problems of maternal and infantile mortality of course predated the war and had been largely attributed to traditional midwifery practices of jieshengpo, who without any knowledge of germ theory often spread harmful bacteria quite unawares, inadvertently causing the deaths of the very people whom they wished to protect. They often worked with unwashed hands and soiled nails, which they might use to stretch the vagina or tear the perineum in order to ease the birth. 
Many jieshengpo worked in rural villages, where farmers saw the soil as a lifegiving force capable of bringing tiny seeds to full fruition each year. Accordingly, a jieshengpo might plunge a knife into the ground before using it to cut the umbilical cord so as to receive a blessing of earth's life-giving powers. After cutting the umbilical cord, she might use mud, animal dung, or ash from the kitchen stove to dress it. Such practices made perfect sense to people in a farming community with no knowledge of bacteria, but they spread the causative agents of puerperal fever (Streptococcus bacteria that enter the body through lesions) and neonatal tetanus (Clostridium tetani, which often live in soil or in animals' digestive tracts and hence entered newborns' bodies through their umbilical cord dressings or soiled knives).$^{38}$ Furthermore, many people believed that malevolent spirits or angered gods caused a child's death, directing their attention away from the actual cause and from proactively preventing future sorrows. ${ }^{39}$

One woman in particular had long been at work to address this problem. Dr. Yang Chongrui (Marion Yang) (1891-1983) grew up in a wealthy Chinese Christian family in Beijing. She earned her MD from the PUMC when it was still the missionary-run Women's Union Medical College (class of 1917), and later studied obstetrics and gynecology at Johns Hopkins University and the Midwives Institute in Woolrich, England (1925-26) before teaching the subjects at her Chinese alma mater. She also toured midwifery schools and medical facilities in England, Scotland, France, Germany, Denmark, and Canada. All of these experiences made Dr. Yang the most knowledgeable person about her field in early-twentiethcentury China.${ }^{40}$ In 1929 Dr. John B. Grant, director of the PUMC Department of Public Health, recommended her to the Nationalist government for an official position as midwifery specialist within the new National Health Administration (NHA). Yang calculated that she could prevent three-quarters of maternal and child deaths if she had solid support. NHA officials, finally convinced, gave her this support; in the single year of 1929 Dr. Yang helped to found and then chaired the National Midwifery Board, became director of the NHA Maternal and Child Health Department, and cofounded (with Dr. Grant), and then directed, the First National Midwifery School (FNMS) in Beijing. Once in these posts, Dr. Yang crafted the education and licensing requirements for new-style midwives and retrained old-style midwives so that they met these requirements, conducting hundreds of trainings..$^{41}$

In this way Yang Chongrui was much like Madame Le Boursier (Angélique Marguerite Le Boursier du Coudray), who 170 years earlier had traveled all over France teaching new-style midwifery to young, unmarried women with the support of Louis XV. ${ }^{42}$ This difference of nearly two centuries put Yang on the defensive. Like many modernizers of her era, Yang Chongrui had a powerful sense of being behind the times. In her writings (discussed below) she frequently compared China with "advanced countries" and used the disparity in maternal and infant death rates to 
incite her compatriots to action. She clearly felt that China would not merit the descriptor "modern" until its people accepted and regularly used the midwifery practices that had become common in many other countries-the same countries whose gunboats had threatened China's shores and whose diplomats had authored humiliating treaties. Under the circumstances it would not have been possible for her to separate conceptually aseptic midwifery from national strength. Hence in her work the two were always conflated, as in virtually all public health texts of the era. Nonetheless, Yang was capable of writing in different registers. For example, when she wrote a report for the American sponsors of her study abroad trip to the United States in 1942, she described China with pride as "the only country on earth where well-educated women bring babies into the world." 43

Just as the new term hushi granted nurses respect by employing the suffix -shi that denotes a learned person, Yang Chongrui created the term zhuchanshi (birthhelping scholars) to designate the midwives with training in aseptic practices as representatives of a new and respectable profession. In so doing Dr. Yang initiated the transformation of midwifery from a humble occupation of mostly illiterate women to a state-licensed and institutionally recognized profession of educated women. ${ }^{44}$ This transformation required associating midwifery with modern science, which Dr. Yang achieved in part by designing a standard midwifery bag that graduates received, containing all the necessary tools for their new trade. Retrained jieshengpo received their equipment in a straw basket, while young women trained in aseptic practices received a bag made of black leather, signaling a distinction between the two groups despite their similarity in training and profession. The most important items among their equipment-all of which signaled the medicalization of midwifery-included sterile scissors with which to cut the umbilical cord and a sterile cord tie and dressing; medicines such as alcohol, mercurochrome, Lysol, and silver nitrate eye drops to prevent eye infections in the newborns; a washbasin in which to wash the newborn; soap and a nail brush for the midwife to keep her hands clean; a face mask and apron for the midwife; artery clamps to use in cases of heavy bleeding; and a hypodermic needle and medicine dropper for administering medicine to mother and child. The bag also included a birth report form and a labor record form, signaling the new connection between midwifery and the state. ${ }^{45}$

This connection led the National Institute of Health to include a page for aseptic midwifery in its 1943 public health calendar. (See figure 24.) The image for the month of March shows a young midwife with rosy cheeks carefully cleaning her fingernails with a nail brush and soap prior to attending to the parturient woman, who is also receiving help from her mother. The midwife has placed her iconic black bag on a chair nearby, and its contents-sterile scissors, silver nitrate, and other medicines-lie nearby, as does a pan of hot water, all ready for the delivery. Clean, white linens adorn everything, including the midwife herself, whose attire 
distinguishes her as a zhuchanshi rather than a jieshengpo. While the former dressed in white (the color of mourning clothes), the latter usually wore traditional clothing such as a padded jacket and a skirt, making the new-style midwife seem all the more foreign ${ }^{46}$ Like the image, the text below it attempted to introduce a whole new set of childbirth practices with the aim of preventing puerperal fever and neonatal tetanus, "still common in China." The text recommended that all married women go to the doctor if their period stopped, that pregnant women visit the health center for regular prenatal checkups, and that postpartum women take bed rest for ten days followed by a checkup after the first month. It said nothing about "sitting the month" (zuo yuezi), the traditional practice of one month's bed rest with a special diet and abstention from washing one's hair or going outside. Taken together, the image and the text for March (the month of International Women's Day) inscribed new practices for the modern mother and signified the indelible connection between womanhood and motherhood in the eyes of the state. ${ }^{47}$

Military nurse Yao Aihua's story of her first birth suggests the power of a midwife trained in aseptic methods. During her pregnancy, Yao's military medical team was stationed in a village outside Laohekou, in northwestern Hubei Province, where a famine had strictly limited the amount of food available and a severe housing shortage meant that she "lived in an old cowshed that stank to high heaven and was full of fleas; [her] body was covered in red bites."

After her fellow medics designated her "a difficult case," Yao went to the city to request the services of a new-style midwife (zhuchanshi), who successfully delivered her baby boy. However, she apparently had contracted an illness from the flea bites and had passed it on to her son in utero; most of his skin had rotted away-so much in fact that "his bones were poking through." Once Yao recovered she was able to nurse him, and he soon grew chubby and healthy, even surviving his younger brother, though his arms remained deeply scarred..$^{48}$

Another story illustrates the impact of urban midwifery training in remote Shanxi Province, and in this instance underscores the influence of Rockefeller philanthropy and the PUMC. Hsiao Li Lindsay accompanied her British husband to Yan'an in December 1941 to offer crucial radio services for the Eighth Route Army. In the fall of 1942 she and another woman walked dozens of miles through mountain villages in Shanxi, both eight months pregnant, in search of a safe place to give birth amid shifting battle lines. Although the entire front-line region had only two qualified midwives, the one who eventually came to deliver their babies, Dr. Yang, had graduated from midwifery school and worked at the PUMC with Dr. Lin Qiaozhi, the woman who later became the PRC's foremost midwifery expert. The baby put herself and her mother at great risk by coming out breech, but fortunately Hsiao Li was strong enough to deliver her in so short a time that Dr. Yang had to sterilize her hands with liquor because the water had not yet boiled. ${ }^{49}$ 


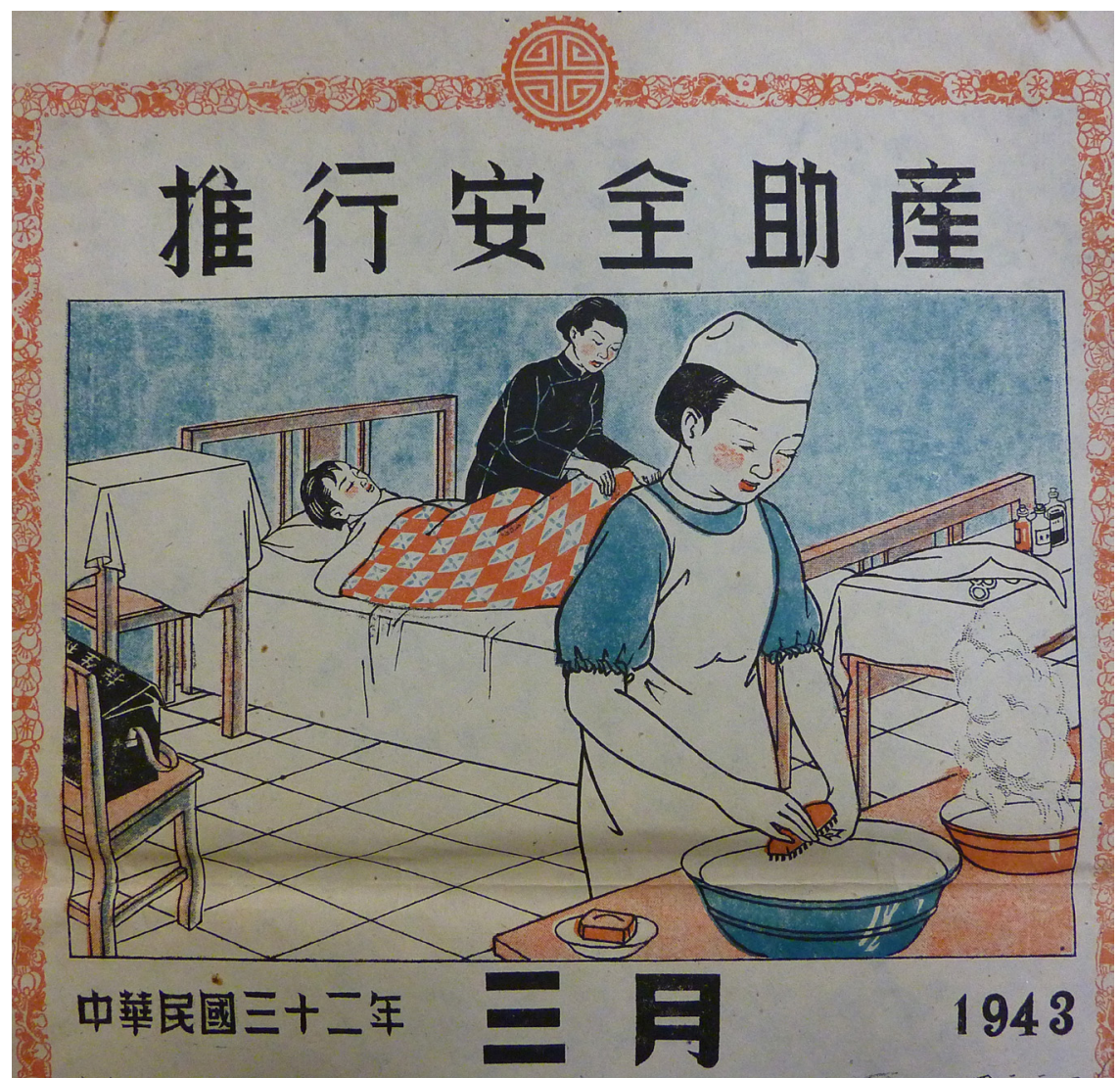

FIGURE 24. March 1943 page of the National Institute of Health public health calendar, titled "Promote Safe Midwifery." NLM ID 101171294, History of Medicine Division Collection. Courtesy of the United States National Library of Medicine.

Recognizing the lifesaving impact of midwives trained in aseptic methods, Chongqing public health officials built the necessary infrastructure for Mother and Child Health work in the wartime capital. The $\mathrm{CBPH}$ set aside resources for $\mathrm{MCH}$ from the very beginning of its operation. In early December 1938, bureau staff began planning four MCH clinics, each with one female doctor and one midwife. Over the course of the next year, the bureau made large purchases of medical equipment in preparation for opening all four clinics, but managed to build only two of the four planned facilities. In the first half of 1940 they completed the original four and opened two more $\mathrm{MCH}$ clinics, for a total of six; then a seventh by August, and an eighth in October 1940.50 This gave the wartime capital three more $\mathrm{MCH}$ centers than the provincial capital of Chengdu..$^{51}$ Over the 


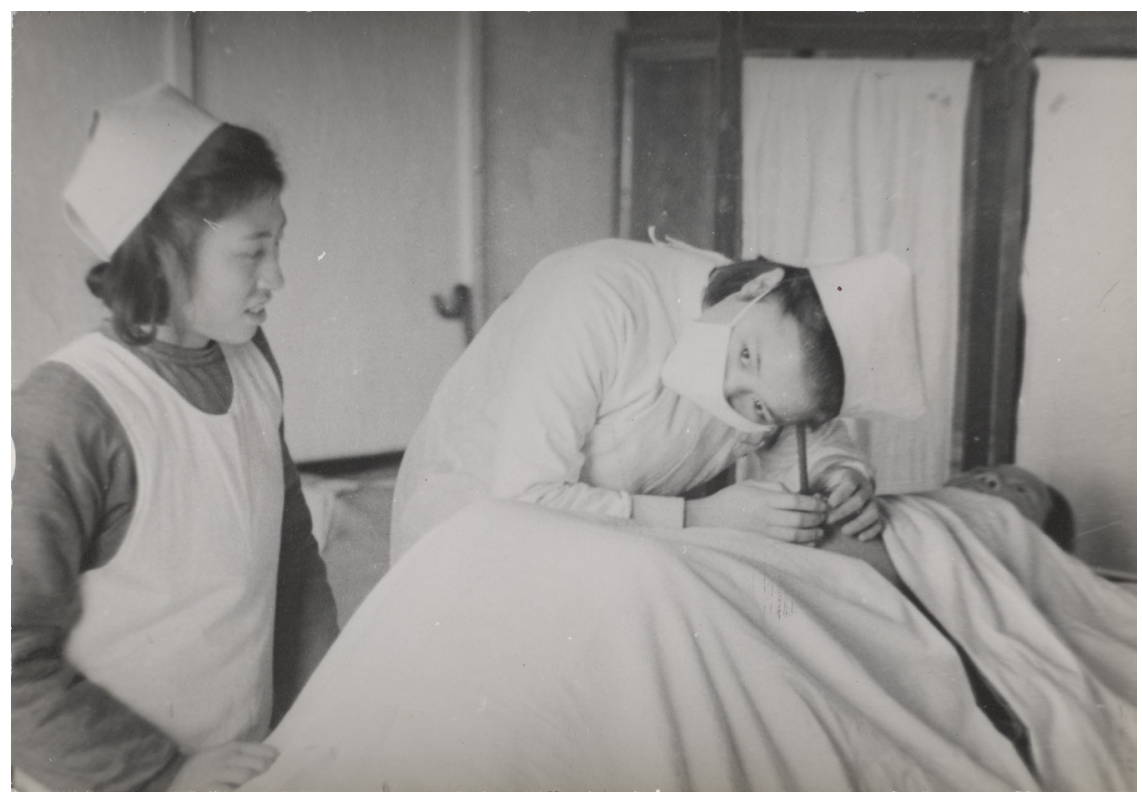

FIGURE 25. Female midwife and nurse conducting a prenatal examination at the National Central Midwifery School in Geleshan, Chongqing. Box 81, folder "Midwifery." ABMAC Records. Rare Book and Manuscript Library. Columbia University.

course of 1940, these eight clinics provided the following services, all free: over 9,000 pre- and postnatal exams, 450 prenatal home visits, over 1,100 births, over 1,100 gynecological exams, and over 1,600 children's health exams. ${ }^{52}$ Clinic staff managed to complete this work despite many setbacks: two of the clinics burned down in air raids; several spent most of the year crammed together in a school with inadequate equipment; two others continued operating out of temples; and two were located in frequently bombed areas, so staff had to spend much of their time performing emergency air raid relief at the bombing sites rather than their usual duties. ${ }^{33}$

The central government heartily supported this work. Each of the eight clinics received a start-up fund of nine thousand yuan from the Executive Yuan and operated in cooperation with the National Central Midwifery School (Guoli zhongyang gaoji zhuchan zhiye xuexiao) (NCMS), which had relocated to nearby Geleshan. (See figure 25.) Midwifery students received practical training at the clinics, and clinic staff received medical training from the NCMS. The two parties agreed that if the clinics got extremely busy, the NCMS would send additional personnel to lend helping hands, and clinic staff would refer pregnant women with special needs to the better-equipped NCMS hospital. ${ }^{54}$ The NCMS maintained high standards of sterility and professionalism. 
Local health officials in Chongqing designated the eight $\mathrm{MCH}$ clinics as centers of "women's and children's health as well as general healthcare work," so staff also performed air raid relief and gave smallpox inoculations and preventive vaccinations (type unspecified), serving thousands each year. ${ }^{55}$ Additionally, in early 1940 the CBPH and the Chongqing Municipal Air Raid Relief Team jointly established a health center (baojian yuan) whose services included birthing assistance (huchan), an infant nursery, and a nursery school. The bureau also demanded that all municipal clinics perform prenatal exams and postnatal family visits, offer free deliveries, and provide nursing care for pregnant women. ${ }^{56}$ The Chongqing Industrial Health Committee also performed seventy prenatal and eighty-three postnatal exams, and assisted twenty-eight births over the course of $1941 .^{57}$

Chongqing still had further need for maternal health services. By 1942 the city's official population had climbed to over 766,000 , and the Bureau of Public Health began planning, and in May 1944 finally opened, its own maternity hospital (chanfuke yiyuan) - with two physicians, five nurses, two midwives, and three departments (obstetrics, gynecology, and pediatrics) - and reported that sixteen patients had already been admitted.$^{58}$ Although the bureau had originally planned for the hospital to have fifty patient beds, it ended up with only thirty, despite the fact that it also spent over two hundred thousand yuan less than the budgeted amount on the hospital's equipment. ${ }^{59}$ However, it soon got a boost. In May 1945, it was united with the Chongqing Municipal Hospital and became its Obstetrics and Gynecology Department, with forty-five beds. ${ }^{60}$ This was the last $\mathrm{MCH}$ facility to open during the war era.

The growth of all of these facilities compounded wartime staffing difficulties. To answer this need, the National Institute of Health, officially opened in April 1941 in Geleshan, operated a training institute for doctors, nurses, and midwives that admitted large classes of students, in which nurses and midwives predominated. ${ }^{61}$ Meanwhile, the Public Health Personnel Training Institute (PHPTI) in Guiyang, Guizhou, trained doctors, nurses, and midwives for civilian health organizations. A photo of the first and second graduating classes of this institute shows a total of 126 graduates, of which women constitute the majority. (See figure 26.)

As this history shows, any shortcomings in $\mathrm{MCH}$ services in wartime Chongqing owed more to wartime circumstances than to lack of earnestness among health authorities and medical professionals. Their perseverance may have been related to the fact that when Dr. Yang Chongrui began midwifery work in Beijing in 1929, that city was designated as a model for the rest of the nation; once the Nationalist government declared Chongqing the wartime capital and Dr. Yang moved there, it became the obvious choice for the new model. ${ }^{62}$ Moreover, as the new capital and home to central government institutes, Chongqing had the infrastructure to become a new center of aseptic midwifery. Nonetheless, many obstacles over which they had no control kept officials from fulfilling their goals. These included 


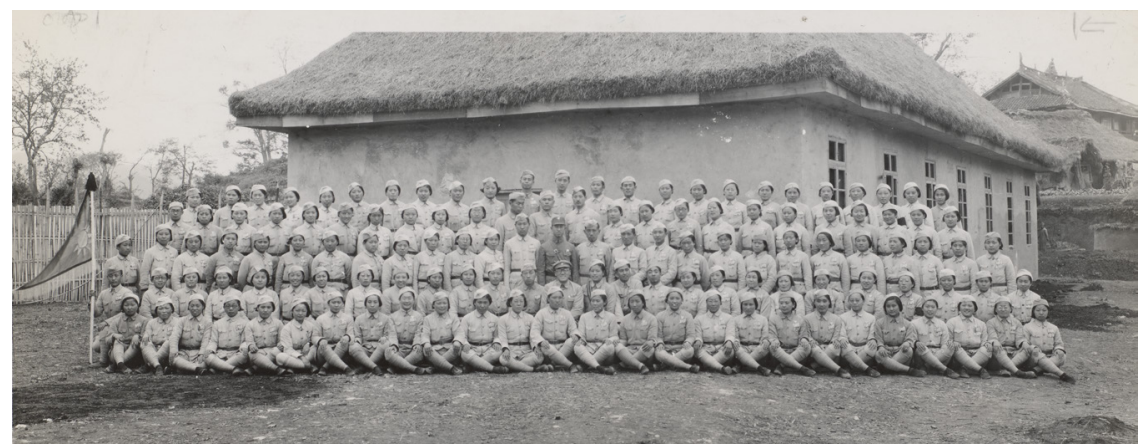

FIGURE 26. First and second graduating classes of doctors, nurses, and midwives at the Public Health Personnel Training Institute in Guiyang, Guizhou. Box 83, folder "NHA and Nursing." ABMAC Records. Rare Book and Manuscript Library. Columbia University.

inflation and financial shortfalls, high staff turnover, bombing and destruction of facilities, and midwives' need during air raid season to divide their time between air raid relief and their usual duties.

Despite these challenges, both local and central health officials committed a remarkable amount of money to institutional midwifery. The resultant quantity of $\mathrm{MCH}$ services in Chongqing contrasted sharply with those in the remote and sparsely populated Communist base area. The Shaan-Gan-Ning Border Region government passed progressive regulations about Maternal and Child Health, but still lacked properly trained personnel in this rural region where local sanitary conditions made childbirth extremely dangerous. By the late war years, health workers in the area managed to establish both a successful obstetrics clinic in the Central International Peace Hospital and a training program for midwives that graduated eighty students in July 1945 . The immediate postwar period witnessed even more $\mathrm{MCH}$ work in the region, demonstrating that lack of resources rather than lack of political will hampered wartime progress. ${ }^{63}$ Even in Chongqing, the financial strain of inflation blocked the ambitious plans of the Chongqing Women's Welfare Society (Chongqing funü fuli she), established in 1942 with the support of Minister of Finance H.H. Kung and Minister of Education Chen Lifu as well as twenty other social benefactors. When the society attempted to open its own maternity hospital, inflation kept even these political magnates from being able to raise sufficient funds, and the plan failed. ${ }^{64}$ Given all of these challenges, it is clear that Chongqing health authorities did everything in their power to improve $\mathrm{MCH}$ in their jurisdiction.

Yet convincing all expectant mothers to avail themselves of these services lay outside the power of all but the most patient health workers. Much of the population was unfamiliar with and resisted hospital childbirth, so simply building and 
staffing the facilities would not ensure their enthusiastic use. ${ }^{65}$ As Qi, a woman who earned a respectable monthly salary of forty yuan as a midwife in Chongqing's Red Cross Hospital, explained,

Women here in the interior do not really like to come to our new-style maternity hospital to seek treatment, so in addition to our regular work we sometimes go to visit pregnant women in their homes and urge them to come to us for checkups since service in our hospital is free, and so far all the women who have used our services are very healthy. Therefore there are some women who come to us, but they're not very enthusiastic about it. As for this, I am hoping that we can increase our education efforts so as to encourage women to better understand our work. ${ }^{66}$

Qi expressed a common mixture of sincerity and didacticism, ending her speech with the declaration that "in the future I hope that we can extend our work into the countryside, because then we can decrease the number of our unlucky sisters who lose their lives. This is our only hope." ${ }^{67}$ Like other middle-class female reformers, Qi believed that she could "educate" women into middle-class behavior (i.e., choosing a hospital birth over home birth). Perhaps she did not realize that many women were already doing precisely what she wanted them to do: bringing sterile midwifery practices and hygiene education to "women in the interior." Their experiences suggest that changing cultural practice was anything but easy, and certainly not natural or inevitable.

\section{CITY AND COUNTRY: MATERNAL AND CHILD \\ HEALTH ACROSS SICHUAN}

Bishan County, thirty kilometers west of Chongqing proper during the war and now part of Chongqing municipality, had the most successful Maternal and Child Health program in all of Sichuan. Chen Zhiqian (C. C. Chen), as director of the Sichuan Provincial Health Administration (SPHA), established the Bishan County Health Center (BCHC) in October 1939 and granted the center "demonstration" status with a healthy budget underwritten by the Rockefeller Foundation's China Medical Board, the NHA, and the Bishan County government. Director Yu Wei managed a monthly budget of 1,559 yuan and lavish headquarters in the old Jiangxi Guild House. By 1945 its budget exceeded that of any other county health center throughout Sichuan, allowing it to run not only the BCHC in the county seat with a thirty-bed hospital, but also eight hospitals and twelve clinics across the county. In addition to receiving better funding, demonstration centers tended to attract the best staff, and the BCHC boasted more than twice the personnel of the center in the provincial capital of Chengdu, and also trained the greatest number of new colleagues. Its medical staff ran a smallpox vaccination campaign and attained complete vaccination across the county by $1940 .{ }^{68}$ Bishan's superior medical services trouble the narrative of Nationalist state neglect of rural areas and suggest 
that further study of Republican-era health work can illuminate the rapid growth of post-1949 health services. ${ }^{69}$

Although the Bishan MCH center (fuying baojiansuo) was not established until December 1943, the BCHC trained new midwives prior to this date and by 1942 performed an average of twenty-five deliveries per month. ${ }^{70}$ In choosing its midwifery students, the BCHC accepted only literate local women around twenty-five years of age, healthy in body and pure in mind (sixiang chunzheng), with gentle spirits (taidu wenrou) and without any previous experience in midwifery. These qualities presumably made the women impressionable and ready to accept the training without questioning the differences between its foundational principles and those of traditional village midwifery. The two-and-a-half-month training's explicit goals included fostering a "spirit of obedience" (fucong jingshen) and training the students to "understand the importance of new-style midwifery [xinfa jiesheng] and decide to earnestly promote it," as well as learn how to "eat bitterness, endure hardship, and obey orders" (chiku nailao fucong zhihui). Graduates had to remain in their village after graduation and continue to work there, reporting on their work monthly, lest they be required to forfeit their diplomas and reimburse the center for all instructional fees. ${ }^{71}$

Stated in this manner, the midwifery training appeared closely tied to the New Life Movement in its aim to produce dutiful citizens who remained devoted to the Nationalist Party. Moreover, it strongly suggests that new-style midwives were charged not only with physical but also emotional labor, since "[o]ne indication of the rising importance of affective labor . . . is the tendency for employers to highlight education, attitude, character, and 'prosocial' behavior as the primary skills employees need. A worker with a good attitude and social skills is another way of saying a worker adept at affective labor." ${ }^{72}$ Since the state saw women as the gateway to the family, and midwives had the power to earn their trust by aiding them in the potentially dangerous moment of childbirth, midwifery clearly signaled its importance to building the affective community of the nation.

Bishan's MCH programs garnered success from the staff members' willingness to honor people's preference for a familiar environment when submitting to a new medical practice. In 1940, personnel made 120 home visits that included fifty-five home hygiene lessons. While far more women received their prenatal exams in hospital (150) than at home (22), midwives attended forty-seven home births and only eighteen hospital births, and conducted home-based postnatal exams for forty-eight women and hospital-based exams for only four women. These numbers show that MCH workers often succeeded in getting women to their hospital once, but frequently had to follow up with women in their own homes. (See figure 27.) The staff most likely recorded the women's home addresses at the first visit and might have shown up uninvited if the time came for a follow-up appointment and the women failed to appear at the hospital. ${ }^{73}$ 


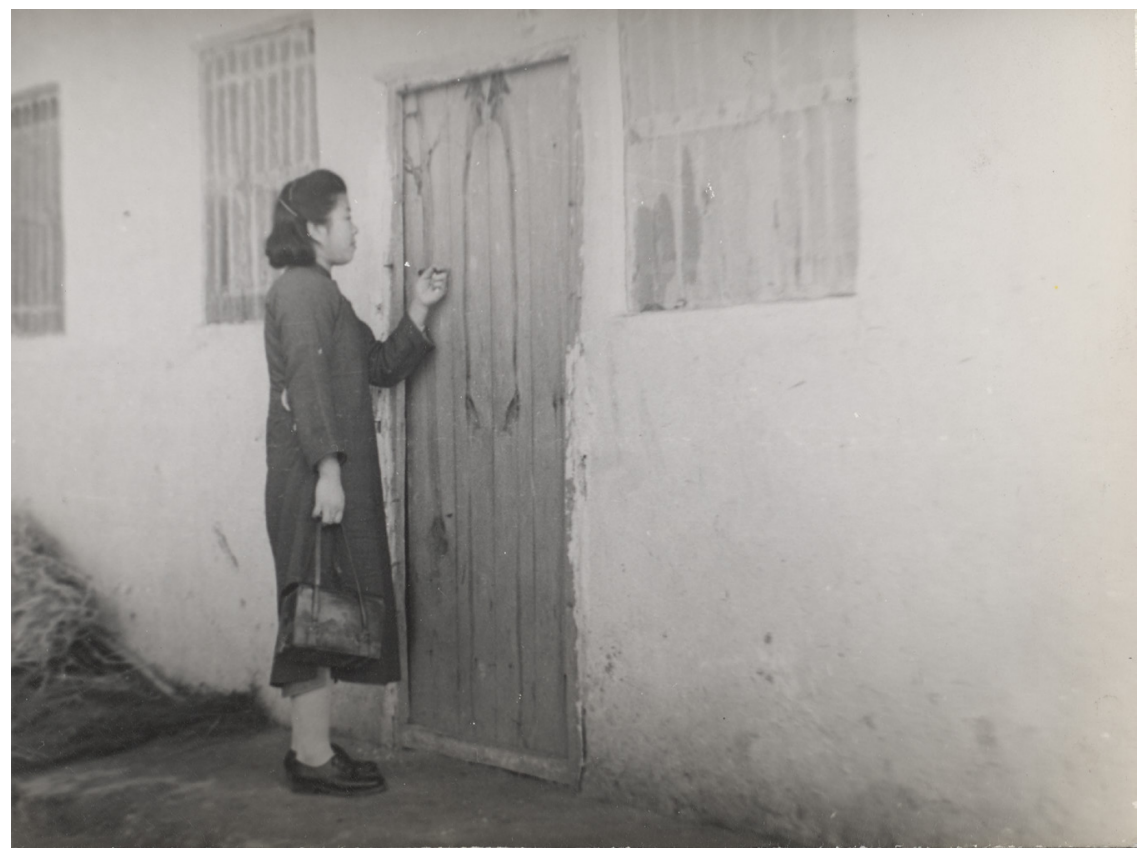

FIGURE 27. A traveling midwife knocks on the door of a private residence, midwifery bag in hand. Box 81, folder "Midwifery." ABMAC Records. Rare Book and Manuscript Library. Columbia University.

When patients did come into the clinic, staff took full advantage of their presence in the waiting room, delivering 115 public health talks to their captive audiences over a six-month period. Mothers [initially] showed reluctance to attend mothers' meetings where staff gave parental advice, with only four people appearing at the sole meeting in 1940, but avidly participated in well-baby competitions (two competitions with 338 people in attendance), and also took greater advantage of the clinic's outpatient services than did men.74 By 1945 Bishan MCH workers had made such an impression that over four hundred women attended mother's meetings, and well-baby meetings continued to draw large crowds. ${ }^{75}$ Furthermore, staff in Bishan performed the greatest number of pre- and postnatal exams and delivered the most babies of any county health center, including that of Lu Zuofu's progressive city, Beibei. ${ }^{76}$

Nonetheless, even at a successful county health center such as this, staff conducted far more general public health activities-such as hygiene lectures and scabies treatments at the county seat's bus terminal-than sophisticated medical services.77 Nurse Zhu Baotian (PUMC, class of 1938) worked in Bishan for several 
years on treating and preventing trachoma, one of the most common ailments among children in both urban and rural China in the war years. This approach therefore accorded with both the dominant model of rural health development at the time and the needs of rural communities. ${ }^{78}$

The BCHC also served as a base from which to conduct work in the county's villages; its forty-eight village health workers accomplished much more by going to the people than by waiting for the people to come to their clinics. This work followed the commitment of Yang Chongrui to bring aseptic midwifery to the people rather than restrict it to elite and exclusive locales. ${ }^{79}$ It also demonstrates the growing influence of the program of roving public health nurses that Zhou Meiyu created in Dingxian (described in chapter 2). County health staff traveled to villages to set up mobile clinics in canvas tents, just as missionaries had done decades before (often traveling illegally to parts of China they were not supposed to visit). They also conducted community health talks, home visits, mothers' meetings, and children's health contests. ${ }^{80}$ In the 1960s, the barefoot doctor program followed this model, with well-equipped clinics in county seats serving as the institutional headquarters for village-based barefoot doctors. ${ }^{{ }_{1}}$

Health work in one village of Bishan County, Xinglong ("Prosperity"), began in late 1939 when the National Christian Council (NCC) launched a Rural Reconstruction project that attracted bright young volunteers. The NCC, with wartime headquarters in Chongqing, aimed to fight rural poverty while discouraging communism and expanding the influence of the Christian church. (The first opened in Xinglong in 1928.) Zhu Xiuzhen's midwifery clinic became the most successful part of NCC work in Xinglong, outlasting the collapse of every other project (the salt cooperative, the church community project, education, and house-to-house economic surveying).$^{82}$ Yet it did not start out this way. It took a lot of work and a bit of luck for Zhu to gain the local women's trust.

Originally trained at the PUMC School of Nursing and the Canadian-run South Henan Union Hospital, Zhu Xiuzhen received her pay from the organization that sponsored most missionary health work in rural Sichuan, the American Methodist Episcopal Mission (AMEM). As a Christian trained in scientific medicine in foreign schools, Zhu embodied a mixture of Chinese and Western values, yet as a Chinese woman she had a better chance of gaining the trust of the suspicious. Zhu's clinic, which opened in early 1940, was Xinglong's first scientific medicine establishment. Being entirely new, it received little attention from most villagers, who barely gave it a sideways glance when passing by, and the first people who sat on its benches asked for no treatment but merely used it as a convenient place to chat with their friends. ${ }^{83}$

Zhu's first success resulted from her patience and understanding that she should allow the village women to use the clinic as they best saw fit: as a gathering place. Once the clinic did become operational, women's positive associations 
with it made it simultaneously a site of social cohesion and a site for medical care. Regarding the latter, Zhu Xiuzhen eventually got her lucky break. A local doctor failed to cure his own infant son of an ailment that Zhu managed to treat, and thereafter referred some of his patients to her and gave her public recognition. Yet it remained even more challenging to make any headway in midwifery, since local women strongly preferred home births attended by jieshengpo. Ignored for six months, Zhu had the chance to redeem herself from negligence when a family called her in as a last resort for a difficult case and she safely delivered the mother a healthy baby. In another difficult case around the same time, the family did not call on Zhu, and the woman died. After this nearly all parturient women wanted Zhu by their side, and by November 1940 she had a midwifery case almost every single day. ${ }^{84}$ No records document how the local jieshengpo reacted to this loss of business, or what they did thereafter to supplement their incomes.

Meanwhile, back in Chongqing, local health officials' emphasis on $\mathrm{MCH}$ produced results. Women in wartime Chongqing went to the hospital infrequently, and stayed as inpatients even less often, unless they were giving birth. In 1940, the Chongqing Municipal Hospital reported 527 female and 904 male patients. ${ }^{85}$ Men constituted 63 percent of the hospital's patients, whereas women constituted 37 percent. In the second half of 1944, 144 women and 434 men received treatment at the Contagious Disease Hospital; its patients were 75 percent male and 25 percent female. ${ }^{86}$ Records from January 1944 through June 1945 at the Chongqing Municipal Hospital show that male patients outnumbered female patients throughout this eighteen-month period, during which men constituted 62 percent of the outpatients and women accounted for 38 percent. The gender imbalance is steeper for inpatients, most of whom paid for their medical services; among this group the male-female ratio was 2.54 to $1.0 .^{87}$

On the other hand, available evidence suggests that adult women in Chongqing considered parturition worthy of a hospital visit. In the last two months of this period, May and June 1945, female inpatient and outpatient numbers leapt ahead of previous averages, precisely because women flocked to the hospital's new Obstetrics and Gynecology Department, which had opened on May 1. In the first month of its operation, department staff tended to 318 outpatients and 56 inpatients. The following month, June 1945, the department serviced 708 outpatients and 56 inpatients. ${ }^{88}$ All available statistics and numbers reported from the $\mathrm{MCH}$ clinics, into the postwar period, show a similar trend, marking a shift in women's preference for a sterile, professional environment rather than their own homes. ${ }^{89}$ In other words, these numbers show a gradual medicalization and institutionalization of childbirth in wartime Chongqing. They likely also reflect social valorization of motherhood as a woman's most important life role, suggesting that family members believed that a woman's own ailments did not justify medical costs, but the arrival or care of a new child did. 
Disaggregating female hospital attendance from widespread resistance to new medical practices is challenging. Women who knew about infectious diseases, or whose wealth and social status made them inclined to patronize a maternity hospital as a form of conspicuous consumption, might have accounted for this spike in visits to the Chongqing Municipal Hospital. Wealthy mothers around the country preferred to give birth in hospitals and clinics "instead of at home attended by what they considered unlearned and unclean traditional midwives," with annual attendance at one women's hospital reaching nearly twelve thousand on the eve of the war in $1937 .^{\circ}$ Wartime Chongqing certainly did have enough wealthy women to account for the sudden interest in the city's first large MCH facility.

These included women such as Zhang Rongzhen, who came from a large middleclass family (with five sons and three daughters) in Shanghai. In 1938 she and her newly betrothed husband moved to Chongqing along with a family servant. A "new woman," Zhang had attended a mission school and joined the girls" volleyball team before entering Shanghai's music conservatory, where she studied choral singing. Once she arrived in Chongqing, she performed as a soloist at a big fund-raising event for the NACWCWRS, affirming her place among middle-class wives whose contribution to the war effort took the shape of financial donations rather than sending family members to battle. ${ }^{91}$ Her husband worked a short while in a factory in the city that produced medical equipment for the military. However, the intensity of the Chongqing air raids in this early period scared the family into hiding in Geleshan, living off savings and pawned jewelry until they had nothing left and chose to return to occupied Shanghai. Roughly one year before they left, Zhang Rongzhen gave birth to their first child, and she chose a small hospital with a famous physician recommended by a friend..$^{92}$

Chongqing had many private midwifery clinics that an expectant mother of means could choose from. Dozens of specialists in obstetrics, gynecology, and children's medicine advertised their services in the Dagongbao, Chongqing's largest, twice-daily newspaper. These included private midwifery clinics, such as those of Drs. Zhang Lianghui, Zhang Yaoxian, Liang Guifang, and Li Shiwei. ${ }^{93}$ Other doctors advertised women's and children's medicines (fuke, xiao'erke) as specialties without mentioning parturition, including Chinese medicine doctors Zhao Fengqiao and Wang Liujie, and scientific medicine doctors Yang Tingmei, Wang Lanfang, Zheng Tuixian, Li Shifang, Huan Shian, and Liang Zheng. ${ }^{94}$ Some of these doctors may have made house calls, since their advertisements did not always list a clinic address. Other doctors mentioned particular hospitals, such as Drs. Chen Yuanchao and Chen Hui at the Red Cross Hospital, and female doctor Lu Jin, who had been head physician at the National Central Midwifery Hospital in Nanjing. ${ }^{95}$ Some advertisements added to a doctor's prestige by listing his or her overseas education, but public letters of gratitude constituted the most special category of medical advertisement. A letter published twice in January 1943 honored 
children's doctor Tang Shaoqian. ${ }^{96}$ Another praised Chinese medicine doctor $\mathrm{Wu}$ Huaibai for curing a little boy who at age four contracted a serious illness that many other doctors of both Chinese and scientific medicines had not been able to treat. $\mathrm{Dr}$. Wu, on the other hand, possessed "the power to bring [the boy] back to life" (you huitian zhili) and cured him in a short time. ${ }^{97}$ The director of the Central Institute of National (Chinese) Medicine, Jiao Yitang, wrote a letter thanking Dr. Zhou Muying for treating his wife's ovarian tumor. He likened Dr. Zhou, head physician of obstetrics and gynecology at National Central Hospital, to legendary physician Hua Tuo of the late Han dynasty, writing, "[W]ithout a doubt she is Hua Tuo come back to life, such is her mastery in women's medicine."98

These stories of midwifery in Chongqing, Bishan County, and Xinglong reveal two key things: that the war brought new medical services to Sichuan, and that women played a central role in spreading those services. Like Hua Tuo reincarnate, female midwives possessed the right skills to inspire awe and confidence, which proved essential to gaining the trust of people who believed cosmological rather than bacterial forces to be at the root of illness. As midwives they needed to gain the trust of women first and foremost, and the fact that women had always played a central role in community health (usually home based rather than clinic based) aided them in this regard. ${ }^{99}$ Young midwives with training at elite educational institutions could introduce new, sterile practices without upsetting local gender dynamics, though they did challenge the power of elderly jieshengpo. While in Chongqing they performed most deliveries in hospital, in the Bishan County Health Center most births occurred at home, and in Xinglong village every woman gave birth at home.

Comparative analysis also reveals a gradation of medicalization wherein rural areas required medical professionals to make the greatest amount of adaptation to local preferences. This owed not to a failure of villagers to be adequately accepting of new medical practices, but rather to a success of villagers and their medical providers alike, who accommodated one another's preferences and found common ground on which to stand together. Yang Chongrui documented some of the adaptations made by the roughly two thousand women who graduated each year from fifty-five schools in twenty-six provinces across China. Yang reported that "ancient customs helped us most, and we observed all of them," citing the opening of something in the room (a door, clothing trunk, or box) to smooth the passage of the child into the world, and preparation of a special meat dumpling "with the dough ends pinched together" on the twelfth day after childbirth to ensure the mother's complete recovery. ${ }^{100}$ Through the vernacularization of praxis-the application of aseptic midwifery in the traditional setting of the parturient woman's home and the adoption of local customs to ease the mother's mind-midwives and mothers saved lives and gradually changed their relationships to each other and to childbirth itself. ${ }^{101}$ 


\section{CREATING MOTHERS OF THE NATION: DR. YANG CHONGRUI'S WARTIME WRITINGS}

Yang Chongrui did not serve continuously as head of the Maternal and Child Health Department at the National Institute of Health (NIH). She spent some time furthering her studies in the United States, fulfilled Song Meiling's demand that she work with war orphans, and briefly resigned from her post in protest of the appointment of a man she interpreted as a political lackey (Zhu Zhanggeng, or C. K. Chu) as director of the $\mathrm{NIH} .{ }^{102}$ However, throughout these interruptions she maintained a continuous presence in the field as an author. Dr. Yang wrote no less than six texts during the war: Diyi zhuchan xuexiao shi zhounian jinian kan (The First National Midwifery School tenth-anniversary memorial publication; 1939); Zhongguo fuying weisheng guoqu yu xianzai (The past and present of maternal and children's health in China; 1940); Fuying weisheng gaiyao (An outline of maternal and children's health; 1943); Zhufu xuzhi: Jiating weisheng ji jiazheng gaiyao (What a housewife must know: An outline of family hygiene and home economics; 1934, 1940, and 1943); Fuying weisheng xue (The study of maternal and children's health; coauthored with Wang Shijin; 1944); and Fuying weisheng jiangzuo (Lectures on maternal and children's health; 1945). Her work also reached a broad audience: individual lectures from this last book appeared, from January to December 1944, in serial format in Funü Xinyun (Women's New Life Movement), a monthly journal published in Chongqing. ${ }^{103}$ While working at the NIH, she simultaneously served as technical expert on aseptic midwifery to the NHA and to the League of Nations Health Organization. ${ }^{104}$

A close examination of Yang Chongrui's wartime writings reveals several key aspects of new-style midwifery, including the reaffirmation of conventional gender roles. In her preface to the second edition of Zhufu xuzhi, a general homeeconomics text originally published by the NHA in 1934 and republished in 1940 and 1943, Dr. Yang premised the book on the idea that women contributed to the nation primarily as homemakers. She wrote, "[P]ersonal health begins with the body, but environmental sanitation, health education, maternal and children's health, school health, and so forth all rely upon the housewife for promotion and implementation. Therefore, in pursuing public health, the training of mothers is a crucial duty." Yang defined personal health as an individual's responsibility, and public health - the health of the national community-as the responsibility of housewives. Put in concrete terms, mothers bore the primary responsibility of "fostering national-racial consciousness" (guojia minzu guannian) in their children. ${ }^{105}$

Dr. Yang also reinforced traditional gender roles by asserting the usefulness of man and the uselessness of woman. She began the section on families and economic prosperity with the declaration that "[i]n China, men are more highly valued because they contribute to the family's economy, while women spend the 


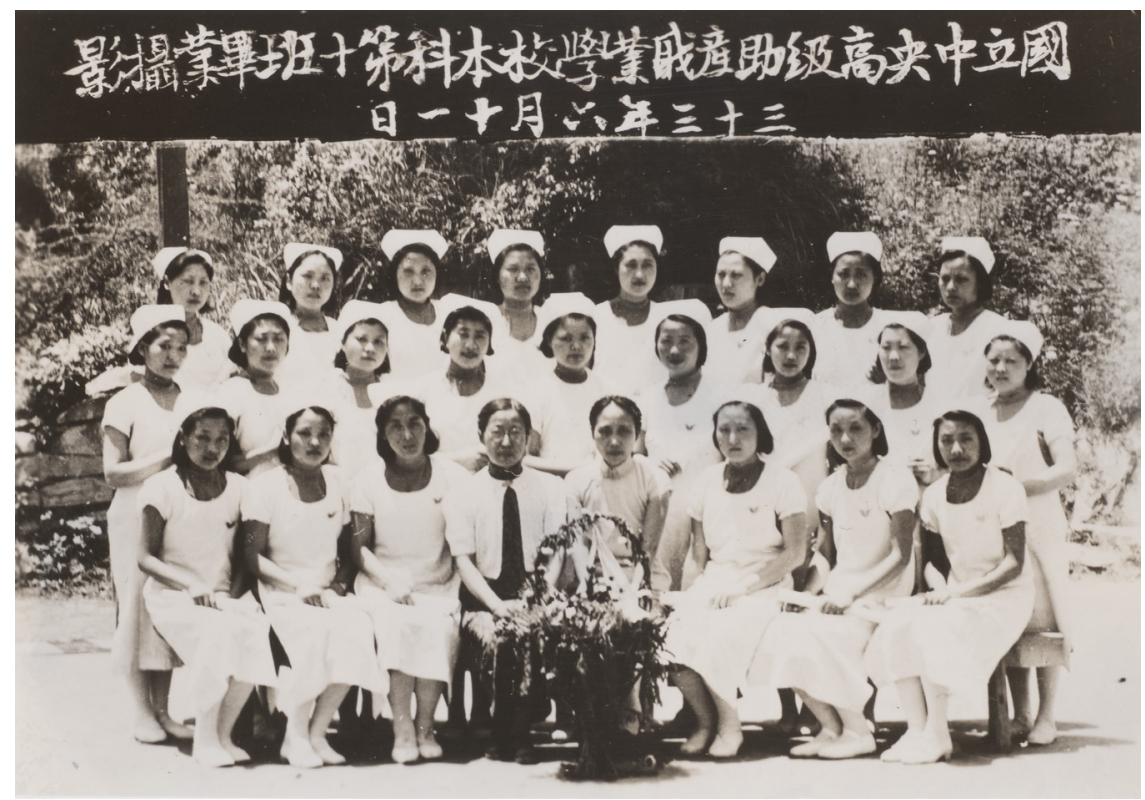

FIGURE 28. Dr. Yang Chongrui (Marion Yang) with the 1944 graduating class of midwives in Chongqing. Box 83, folder "NHA and Nursing." ABMAC Records. Rare Book and Manuscript Library. Columbia University.

majority of their time taking care of the children and thus cannot become productive workers and consumers." ${ }^{106}$ This equation stood even though it contradicted the ideological premise of the entire book: that a mother's work in the home is the very foundation of a healthy nation. Moreover, she wrote that a mother must raise her children to be financially independent and thus able to contribute to the national economy, making child-rearing itself economically productive, but she did not directly acknowledge this fact in her text. ${ }^{107}$ Yang also blamed wives for overstraining their husbands by having too many children, as if wives faced no pressure from the greater family to procreate but made unilateral decisions to get pregnant repeatedly on their own (though she neglected to explain how such an immaculate conception could occur). Despite describing housewives as a useless strain on the family, Yang charged them with responsibility over all matters pertaining to the health of all family members, including everything from food safety and regular bowel movements to avoiding public napkins and teacups so as to guard against contagion of tuberculosis, trachoma, and "venereal disease." This led to the conclusion that a family's weakness all originated with an ignorant housewife, and that only an educated and (re)trained housewife could strengthen the family. ${ }^{108}$ Yang's attitude accorded with that of home economists, who "viewed 
management of Chinese homes (domesticity) as central to national concerns." 109 In other words, Yang outlined the duties of "mothers of the nation" and reinforced the idea that a mother's sphere of influence extended far beyond her own home to encompass the entire "national family" (guojia), even as she described housewives as profligate idlers.

Yang Chongrui's other texts offer some clues for resolving this apparent contradiction between a housewife presumed ineffectual in her own home while simultaneously carrying the weight of the entire nation. Simply stated, her writings betray her class prejudice. Like other highly educated middle-class women, particularly those who had traveled or studied abroad, Yang believed that she knew the proper way of doing things, that this way differed almost entirely from the manners of her poor compatriots, and that she therefore bore the responsibility of schooling them in "proper" behavior. This attitude had characterized the scholarofficials of imperial times as well as their descendants, the intellectuals of the May Fourth generation, and in the 1930 s it found its best expression in the New Life Movement (NLM). As previously explained, middle-class ideals dominated the NLM and gave activists a source of self-righteous pride in transforming the poor into "self-respecting and worthwhile citizens." 110 In other words, Yang Chongrui and her fellow activists believed that lower-class housewives had the potential to deliver the nation to prosperity, but only once educated women had transformed their thinking and behavior patterns to conform to middle-class ideals.

This attitude appeared in a midwifery textbook that Yang coauthored with Wang Shijin, a public health lecturer in the National Central Midwifery School (NCMS). First published in Chongqing in 1944, and again in Nanjing in 1947, Fuying weisheng xue (The study of maternal and children's health) originated with a request from the Ministry of Education's Medical Education Committee for a suitable textbook for the NCMS. This project addressed the great need for textbooks that schools in Free China experienced during the war, and replaced a 1943 text that Dr. Yang had written for that purpose but believed inferior, Fuying weisheng gaiyao (An outline of maternal and children's health). ${ }^{111}$ Given that it was designed to serve as the primary textbook for the central government's own midwifery school, Fuying weisheng xue provides a good snapshot of contemporary political ideology and how it inflected the original goal of diminishing maternal and infant mortality toward strengthening the nation and race. The very first lines in the book illustrate this dynamic:

Maternal and children's health is an important part of public health. It utilizes science and technology to implement health and sanitation for neonates, infants, and young children. ... It prevents diseases, promotes health, lowers mortality, ensures the complete physical and emotional health of the next generation, and promotes a healthy physique in the entire nation-race $[\operatorname{minzu}] .{ }^{112}$ 
This formulation completely effaced the women themselves, transforming them into ovaries and uteruses designed to carry the next generation into a healthy and prosperous future. While a mother may appear to be at the center of motherhood, "she is often evacuated from this position by a discursive focus on the child."113 Moreover, the discursive focus on the child-as-nation and child-as-race constitutes a double evacuation, since the child in utero is already displaced from his or her own existence and representative of-and physically responsible for the health of-the entire nation and race, even before its birth.

The story from Sichuan's Bishan County illustrates how the double evacuation of women and children from their life-meaning could occur alongside life-affirming practices. Recall that in the small town of Xinglong, foreign and Chinese volunteers from the National Christian Council launched a variety of social welfare projects. They performed local surveys, taught adult literacy classes in the church, opened an aseptic midwifery clinic, and planned a salt cooperative to provide affordable salt to the local community. None of their work proceeded without the explicit approval of local members of the well-established secret society, the Paoge ("Robed Brothers"), and because the salt cooperative threatened the society's profits in black market salt, one influential man shut everything down. Everything, that is, except for the midwifery clinic. Because the work of the midwife did not challenge but affirmed local patriarchy, and because she had demonstrated to the fathers that she could keep their wives and infants alive through complicated deliveries, the midwife alone continued her work after this disastrous social conflict. ${ }^{114}$ Aseptic midwifery simultaneously protected women's and children's lives and affirmed patriarchy, and it therefore survived the demise of all other social work in Xinglong. Likewise, Yang Chongqrui and Wang Shijin wrote in this manner because they were describing their own social reality in a culture that placed so much emphasis on children that women appeared absent from their own physical experiences, and so much emphasis on the nation's future that children were absented from their own childhoods.

Yang and Wang also lay bare their devotion to science, writing that between the childbearing ages of fifteen and forty-five, women "require the work that personnel trained in professional, scientific medicine and technology can perform in order to protect their health." ${ }^{115}$ This formulation empowered not women, but scientifically trained personnel, who treated the parturient woman as a patient, with the Chinese term meaning literally "sick person" (bingren). ${ }^{116}$ The use of this term clearly signaled the medicalization of childbirth, and constituted a not-so-veiled critique of all elderly midwives who had not undergone retraining to learn aseptic techniques. In this manner, while maintaining the overall focus on saving women's and children's lives and improving their health, $\mathrm{MCH}$ professionals, compelled by a love of science, utilized a means of achieving this goal that could easily have been more disempowering than empowering to an expectant mother, particularly 
for those who preferred to labor at home with the aid of a jieshengpo respected in the community.

The authors described both women and children as in a compromised state, in constant danger of contracting life-threatening diseases, and therefore in need of "professional science and technology" to step in for their own "relatively weak immune systems" and save them from puerperal fever or lifelong gynecological disorders, and their offspring from neonatal tetanus or conjunctivitis. ${ }^{117}$ In this sense wartime discourse on MCH mirrored the Song-dynasty argument of women ruled by blood and inherently weaker than men-a medical discourse that male physicians had challenged in the Ming and Qing dynasties. ${ }^{118}$ In a discussion on menstrual health in Zhufu xuzhi, Yang advised menstruating women, "[T]o care for your nerves, do not read overly stimulating texts or picture books so as to avoid arousal. One must also endure and control the excitement of romantic feelings (since during this period it is easiest to be overstimulated, making one's happiness, anger, sorrow, and joy abnormal)."119 By depicting women as particularly volatile and prone to emotional abnormalities during menses, Yang recycled centuries-old notions of female weakness and refuted more recent challenges thereto. ${ }^{120}$

In other ways Yang Chongrui was fully embedded in her era. Like other intellectuals coming of age in the early twentieth century, she believed so fully in the power of science and its indispensable tool—data—that she exhibited a "passion for facts" and a certainty that all successful work began with gathering statistics. ${ }^{121}$ In their textbook, Yang and Wang backed their depiction of the dangers of childbirth with statistics on maternal and infant mortality. Citing first the NHA estimates for China with which this chapter opened, they then compared their own country with 1926-36 data from "other countries with advanced health," including Australia, Austria, Chile, England, Wales, France, Italy, Japan, New Zealand, Scotland, Spain, Sweden, Germany, and the United States. They then referenced the argument of an Englishman in order to affirm their claim that high mortality eroded the foundation not only of individual families, but of the entire nation and race. ${ }^{122}$ In addition to painting China as "Europe manqué," Yang Chongrui and Wang Shijin used this international comparison to leverage their position as $\mathrm{MCH}$ specialists who spent their days worrying about how to save mothers and newborns from premature deaths. ${ }^{123}$ This framing also demonstrated that Yang and Wang paid close attention to the worldwide discussion of $\mathrm{MCH}$ and saw themselves as contributors thereto. As such it further legitimized their own role as specialists and impressed upon student readers the idea that China needed to "catch up" to the "advanced" countries in order to be considered part of the civilized world. In the authors' view, this process began with women and children-or, stated more honestly, with professionals such as themselves teaching women and children how to behave. Thus they argued that, just as a house needs a solid foundation, the nation needs a base of strong women and healthy children in order to build its 
future prosperity. This required "improving racial health" by conducting premarital examinations to determine the genetic fitness of a couple; if either partner was determined to be a carrier of a contagious disease, then, the authors declared, "we can encourage them not to marry or sterilize them." Yang and Wang resorted to eugenics in order to establish the importance of $\mathrm{MCH}$ to "strengthening nationbuilding and establishing a healthy racial family" (zengqiang guojia jianshe, shuli jianquan jiazu). ${ }^{124}$

Pithy texts such as this can easily obfuscate the authors' true intentions. In an era of heightened ideology and propaganda, people often learn to couch their arguments in fashionable clichés, regardless of their own feelings about the subject. ${ }^{125}$ Intelligent use of politically permitted metaphors and culturally approved analogies can win adherents to a health policy or medical practice far more readily than can resisting the demands of the day. Therefore, Yang Chongrui and Wang Shijin's copious discussion of the nation and race in a textbook written at the behest of a central government agency does not necessarily preclude the possibility of a female-empowering project-by and for women-masquerading as a nationempowering one. Nonetheless, Yang and Wang likely did believe in eugenics, or youshengxue, the "study of optimal birth." A popular ideology in Republican China, eugenics merged with the earlier concept of fetal education (taijiao) to stress the pregnant or parturient woman's vulnerability and imperfection, as well as the idea that her responsibility as mother began with conception rather than birth. ${ }^{126}$ But while fetal education drew on Confucian morality to reinforce a mother's central importance in the creation of life, here the authors used science as a lever with which to unseat women from their own birthing process.

In addition to their belief in eugenics, Yang and Wang clearly wished to empower the state in its role as health provider. The promise of state medicine had charmed nearly all health professionals by the early twentieth century, and since the Japanese assault made the achievement of a powerful Chinese state not only a cultural and political goal but also a military and economic imperative, few dared to speak out against state medicine in the war years. ${ }^{127}$ Thus, our two authors argued that $\mathrm{MCH}$ workers wove a veritable red carpet upon which the state could march into people's homes:

Improving mothers' and children's health can be the way inside the homes of the people whom we wish to touch with other health measures. For example, the work that is involved in educational propaganda, moral cultivation, and other health work, such as epidemic prevention and environmental hygiene, can be brought before the people smoothly and effectively by mothers' and children's health workers who have earned the housewives' trust. ${ }^{128}$

This framing both legitimized $\mathrm{MCH}$ as a potent tool for extending state power and affirmed the link between health work and central governance. The authors as- 
sumed the voice of the state when they referenced "people whom we wish to touch with other health measures." This points to an unavoidable dynamic of twentiethcentury health activism. No one, not even Rural Reconstruction activists, could do effective work without the support of the state, yet inviting state support required rendering themselves and their work legible to male politicians who prioritized the state's needs. Thus, motherhood and childbirth had to bear upon state building, national salvation, and social reform in order to gain political legitimacy and state funding. ${ }^{129}$

In other words, in order to gain a place for themselves in the professional world, public health nurses and $\mathrm{MCH}$ workers had to channel state power into the home, but in so doing they extended the power of state patriarchy into spaces that had previously belonged to the family patriarch (the home and the womb). In effect they transferred power over women's wombs and their issue from individual men of the family to the male collective of the state, all while preserving gender hierarchy. The assertion that caring for the family constituted service to the greater collective squared with home economists' esteem for women's domestic work as a cornerstone of a strong nation. Moreover, treating families as "legitimate targets for public reform" allowed professional women-home economists, nurses, and midwives alike - to "[clear] the way for a smoother operation of state power." ${ }^{130}$ In this way, both home economics and $\mathrm{MCH}$ paralleled general public health work in linking individual units - such as the nuclear family and the individual body-to the collective nation and race. Yet the manner in which they arrived at this goal affirmed the goals of state patriarchy and robbed them of any opportunity for true gender equality.

The last line in this passage indicates the most crucial issue in aseptic midwifery: the authors placed their own faith in, and asked state officials to believe in, health workers who had "earned the housewives' trust." Trust was the fulcrum on which all the work of strengthening the race and building the nation rotated. As with nurses whose tender healing touch transformed irate soldiers into willing fighters, young midwives equipped to perform the emotional labor of "earn[ing] the housewives' trust" served as a proxy of the masculinist, necropolitical state in the most intimate moment in the life of a woman and child: birth. By entering a woman's home and body, a young midwife trained in aseptic techniques accomplished a triplicate task: securing the lives of the mother and child even as she opened them to the discursively life-negating effects of state control and severed their relationship to well-known elderly midwives in their community. As long as the pregnant woman trusted her and focused on the first of the three goals, a midwife's labor could multiply to produce an outcome that far exceeded the event and space of childbirth. Like military nurses, midwives simultaneously affirmed and denied life (though in the latter case the denial hinged on discursive evacuation from life meaning, rather than augmenting a direct threat to physical safety). 
The centrality of trust in women's health care echoes its centrality in the making of scientific meaning. Trust did more than empirical evidence to solidify faith in science, at least for seventeenth-century natural philosophers in England, and the same principle operated in wartime midwifery: a trusted midwife like Zhu Xiuzhen, who respected rather than upset local custom, experienced a sudden explosion in demand for her previously ignored services. In other words, just as seventeenth-century Englishmen gained access to the status of truth maker in the early days of science by adhering to codes of gentlemanly conduct so as to be perceived as trustworthy, the empirical evidence that young midwives could save lives was not interpreted as such until they had gained the trust of the community. ${ }^{131}$

Once young midwives and public health nurses gained a trusted status within a given microcommunity in China (a network of villages or an urban network like that of Zhang Rongzhen, whose members recommended trusted physicians to each other), their work proceeded smoothly. This was the foundational principle of the barefoot doctor program, in which young people who already had the respected status of the peasant class in Maoist China worked in their own communities. ${ }^{132}$ Likewise, the health work in Dingxian and other model sites rested on community members' trust of the people offering the otherwise foreign services, and the most successful activists fully understood this principle. Zhou Meiyu's public health nurses ate and slept with the people they served and deputized schoolchildren to recruit their family members to vaccination drives. Chen Zhiqian carefully selected the people who taught village health workers out of recognition of the importance of trust. He wrote in his memoir, "I was well aware that the success of the training program depended not only on what was taught but also on the personality of the teacher ... [because] mutual respect and confidence must be developed on an individual basis." ${ }^{133}$

The role of trust in establishing scientific "truth" also offers a clue for unraveling the failure of spreading aseptic midwifery in Dingxian, the same place where general public health work resulted in resounding success. In Chen Zhiqian's reporting, midwifery reform "was impeded by prevailing social attitudes and economic conditions," of which he cites mothers-in-law's insistence that their daughters-in-law give birth at home (even if the latter were willing to go to the clinic), and local midwives' resistance to retraining classes. Yet Chen directed his incisive analysis of the cultural effects of "social attitudes" only at the villagers, and not at himself or his coworkers. In contradistinction to his frequent declarations of admiration for the villagers, he described the elderly jieshengpo-who, it must be emphasized, had gained that title by earning the trust of their community members-as "ignorant old women," betraying his utter lack of respect for them and their place in local society. They responded in kind; they "resented the young, unmarried woman we selected as the trainer ... [and] regarded her as an inexperienced upstart." As "an outsider of only twenty-five years of age," the trainer could not gain the status of "a trustworthy person." The reformers eventually learned to 
gain elder midwives' trust by training one of their own young family members, who "would receive the older woman's support in her new role"; but they could not ensure that these young women had enough time to devote to midwifery, so even that innovation failed. ${ }^{134}$ In the end, the very reformers who understood the necessity of trust "themselves had a hard time trusting midwives," and the work of promoting aseptic midwifery constituted a notable failure in Dingxian. ${ }^{135}$ They also faltered in reforming marriage practices, and in the analysis of Kate MerkelHess, both failures resulted from the fact that villagers experienced the attempts to change childbirth and marriage practices as an effort "to trample [their] power and expertise," so they resisted mightily. ${ }^{136}$

\section{CONCLUSION}

In 1929, in his capacity as the first vice minister of health, Liu Ruiheng (Dr. J. Heng Liu) expressed a hope for "the gradual extinction of old-style midwives and the substitution for them by the modern-trained." ${ }^{137}$ From the perspective of modernizing health officials, wholly wedded to germ theory and committed to using this knowledge to fulfill what they deemed their responsibility to the public, the war constituted a dangerous interruption of lifesaving work. Yet the threat of conquest brought the discursive meaning of motherhood to the fore. Charged with mothering the nation, women came under special scrutiny as the targets of social and political reform. Both $\mathrm{MCH}$ workers and state officials believed that childbirth and motherhood should be performed in a specific fashion that adhered to the tenets of germ theory and middle-class values. This aligned $\mathrm{MCH}$ with the broader aims of public health and enlisted midwives and orphan relief workers in the project of creating not just healthy but also dutiful citizens. The war pushed people to prioritize the needs of the national collective and treat individual men, women, and children as possessions of state and society. This manifested itself in efforts to put orphans in the battlefield, Yang Chongrui's writings on scientific midwifery, and statements such as that of British-educated physician Sze Szeming (Shi Siming), who expressed regret that Song Meiling had gone to the United States in late 1944 with the claim that "[s] he belongs to China and should be with her husband." ${ }^{138}$ As the foremost shaper of Chinese midwifery, Dr. Yang had a powerful influence on her readers. Dr. Sze's opinions also mattered. As personal secretary to Foreign Minister Song Ziwen (T. V. Soong) during the war, Washington, DC-based staff member of the United Nations Relief and Rehabilitation Administration (UNRRA) after the war, and one of the three men who engineered the creation of the World Health Organization in 1948, Dr. Sze had a profound influence on Chinese statecraft and postwar global health. ${ }^{139}$ In one sweeping statement he implied that marriage is a man's ownership of his wife and equated this conjugal possession to a country's proprietary relationship with its (female) head of state. 


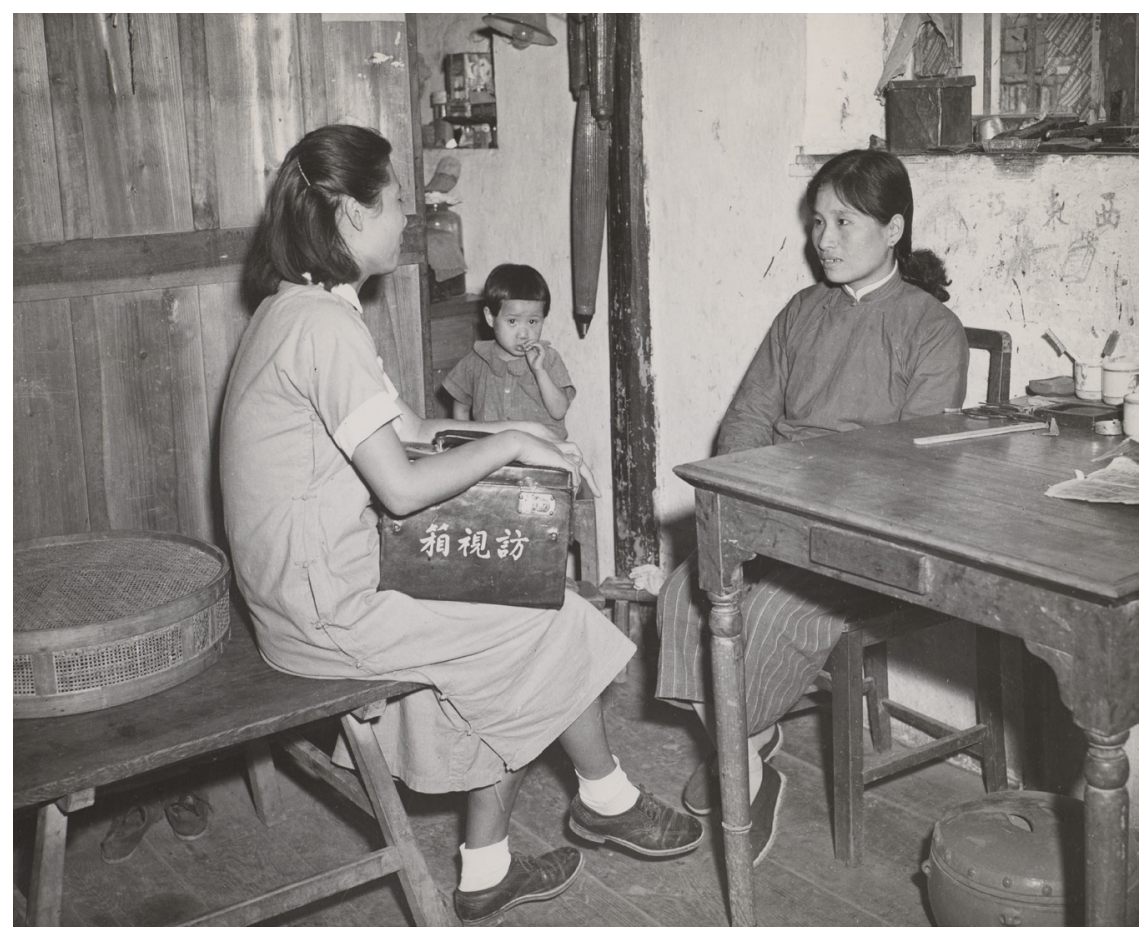

FIGURE 29. A visiting nurse instructs a mother in her home near Nanjing, late 1940s. Box 8o, folder "Health Station Clinics." ABMAC Records. Rare Book and Manuscript Library. Columbia University.

Aside from the power of discourse, women's contributions to the national family through motherhood and midwifery exceeded the rhetorical. Women working in the field of Maternal and Child Health made notable achievements that saved the lives of birthing women and children across Sichuan Province, even in remote villages. Rural women actively chose aseptic midwifery once they recognized it as a lifesaving practice, and midwives' willingness to accommodate to rural culture made this resource available to them. In the village of Xinglong, midwife Zhu Xiuzhen patiently cultivated her relationships with local women, whose absolute trust she needed in order to do her job. At the same time, midwives' status as women working in a traditionally female field allowed them access to private homes. They therefore became indispensable servants in the mutually reinforcing projects of enveloping the southwest into the national body and introducing state power into the home.

A photograph of a traveling public health nurse visiting a young mother in her home near Nanjing in the late 1940s documents a continued need for trust in medical encounters, as well as a postwar continuation of women's role in state- 
sponsored, home-based care. (See figure 29.) While the facial expressions and body language of mother and child suggest a measure of shyness and trepidation, the nurse sits comfortably across from the mother in a posture that implies humility, with a "house-call box" (fangshi xiang) perched on her lap. The photo tells us nothing of the words that they exchanged, but does show mother and nurse in similar attire, apparently deep in conversation. This photograph was taken a few years before Yang Chongrui, who had long worked with and in the Nationalist government, acquired the status of political pariah while her most talented student, Lin Qiaozhi, became the beloved, iconic heroine of modern midwifery in the People's Republic. ${ }^{140}$ With this apparently smooth transition from one representative leader to the next and one state regime to another, the work of promoting aseptic midwifery continued in intimate encounters inside women's homes across China. 